\title{
A FINAL SHOWDOWN AGAINST STREAMING GIANTS
}

\author{
Aritra Basu \\ Writer/MPhil Research Scholar, University of Delhi (India)
}

\section{PROLOGUE}

In the year 2121, Satyajit Ray, Adoor Gopalakrishnan, Shyam Benegal, Mira Nair, Mrinal Sen, Ritwick Ghatak, Anurag Kashyap, Anand Patwardhan, Bhaskar, Manju Borah, Jyoti Prasad Agarwala, and many others joined hands together in their common fight against the streaming services in India. A week ago, Netflix had joined hands with Amazon Prime, Hoichoi! and Disney+ Hotstar to declare that they would only be streaming films that are made by English speaking people. Addatimes and SonyLiv had tried their best to protest, full credit to them, but the sheer power of the names of Bezos and Disney stalled them into a corner. The dusk of Indian cinema was near; the journey was coming to an end.

\section{Act i Scene I}

1 Bishop Lefroy Road. A dilapidated house with some dusty photographs of Ray's golden years. The living room is resplendent with the smell of dead creativity. A smoke cloud from several pipes clouds the vision. The smart TV plays an expired Netflix trailer of Pather Panchali.

Slapstick clicks. “...camera, and action” is heard from a distance.

Ray: Friends, Filmmakers, Foes...

Ghatak: Who on earth is your foe here?

Benegal: Why, The Enemy of the People, of course! This pedantic, fascist government, which has managed to impose English upon us.

Ray: Precisely! Though I know not how or why I address them

Ghatak: Yes, who would have thought that they would have grown tired of their favourite Hindi so soon?

Benegal: Oh, that was when they realised that someone managed to rule unopposed in India for almost two decades using English as their divisive and dividing sword. Thus, they cornered English and made it their own. 
(A whisper is heard. Someone says, 'for even the walls have ears. I mean, CCTV cameras with mics')

The crowd asks, "Who spoke?"

They realise it is probably the spirit of free cinema, and by extension, of free art. They sit upright.

Gopalakrishnan: This is our last chance. The halls are closing out in the coming new year. We barely have three months.

Kashyap: Yes, but who will direct?

They all look at the exactly two-hundred-year-old man. The 2nd of May was barely a month ago.

Ray smiles wryly. He looks at Borah and Agarwala.

[Aside

Borah: We could have done it. Many think Assamese is a dead language these days. Recently, it was de-listed from the 8th Schedule as well. This is our chance.

Agarwala: Oh no Manju, this is no time for selfish motives. We must remember that we are here for a greater cause. To have this effort recognised by the West, we must hand over the reins to the man who received one of the greatest western accolades in his day.]

Sen: The days are gone by where anyone could direct any film they want to. You now have to take the script to the Censorest Board, which was built upon the ruins of the Censor Board of our times. Upon approval, you must take it to the home minister Vomit Shah, the great-grandson of the great divider.

Ray takes out a smartphone from his pocket!

Ray: Why, these phones are said to have good cameras. Hundreds of megapixels. There is a dusty selfie stand left behind by my grandson Souradeep that we can use as a tripod, and a spare trolley. Who needs to know we are shooting a feature film. We could be making Instagram reels for all they care.

Patwardhan: I have always admired your ingenuity, Ray. Be it using a live tiger in Hirak Rajar Deshe or shooting from the dicky of an ambassador, you always had an ex-factor about your work.

Kashyap: Yes sir. I had done a late $\mathrm{PhD}$ in my life, and it was on the transition from black and white to colour films in the works of Satyajit Ray, and I discovered so much about colours and framing I had no idea about. Tell me, Ray babu, was it all a part of a large scheme, or...

He is interrupted by Ghatak and Sen simultaneously.

Ghatak: Oh lord, no! It was the spontaneous overflow of powerful emotions... Sen: Nuh-uh! Powerful cinematography recollected in tranquillity. 
Nair: If y'all are done quoting the Romantics, may we please shift our attention back to this dystopia? Or is your Xanadu too little too dear to your souls which rest in denial?

Borah: Let us then shift to a more open space, where we can discuss this more freely.

The directors run to the back of the stage and the stage rotates on its axis. The scene is now at Moulali, a few steps away from the bus stop of what was once called "Jora girja" (double mosque). 10 in the morning. Everyone from Scene I except Mirnal Sen have come together for a meeting.

A 221 bus passes by, shouting "Kalamnadir, Beckbagan, Minto Park...”. The bus stop now reads, "Bharatpur."

Ghatak: These dumb idiots did not know that Moulali is a combination of Maula and Ali. That's why the name was spared. I still miss the mosques, though.

Gopalakrishnan: It's been a hundred years since a decent Bengali film was made.

What was the last one?

A flute plays in the distance. Riddhi Sen (A Bengali actor from the twentyfirst century) emerges with the first and last Bengali Filmfare in his hand.

Riddhi: Nagarkirtan.

"Right", murmurs someone from the crowd.

Enter John Abraham and Mani Ratnam.

Gopalakrishnan: Ah, finally! My compatriots from Tamil Nadu and Kerala are here. You people managed to hold them out till they cared to conduct elections. Ratnam: It all began on the 7th of April, a hundred years ago. The Film Certificate Appellate Tribunal was abolished by the Ministry of Culture. Do you remember how pathbreakers like Lipstick Under My Burkha were released after the intervention of the Appellate?

Abraham: Yes, who could forget! The decades around the turn of the millennium were the finest that Indian cinema ever saw.

Ghatak: And we were fools to believe that the streaming service giants are here to help; that they would release those films of ours for the masses which the censor board did not allow to be released in theatres. Who knew the Covid19 pandemic would hit the theatres so badly that they would run out of business and existence within 2030?

Someone runs into the scene. It is not clear who it is, because of the pollution in the air. They seem to be carrying something in their hands.

Ghatak: Who is it? Sen, is it you?

Sen: It is me indeed. Look what I have with me 
He shows everyone a reel (not Instagram; a physical reel with film inside it)

Gopalakrishnan: Where on earth did you get that.

Kashyap smiles wryly. As a former resident of Bombay, he knows that the city is helping them fight back. After all, it was the two cities of Calcutta and Bombay which had produced most of the stellar films and directors of all times.

Ray: We are digressing, people! We need to decide on the subject matter of the film and how it would be shared with the masses...

Riddhi Sen: Manik babu, probably you have forgotten that at the advent of the twenty-second century, the Government of India made it mandatory for every registered citizen to have their WhatsApp account linked to their Passport and Aadhar Card. We can use that!

Everyone rejoices at this prospect. They mutually decide that the content of the film would be about a slow degradation in the reception of films and the past glory in which Indian cinema used to bask. Since there are no professional actors (except Riddhi), the directors and Riddhi Sen decide to act themselves. After all, in every director sleeps the essence of a magnanimous actor.

Borah: Should we start the show with a quick recap of the hundred golden years of Indian cinema?

Ghatak: What good will that do? They already teach that to kids these days, as a part of their "Ancient Art Forms" course. Out target audience, let us not forget, are not the octogenarians who contributed largely to this scarcity... err... let's call it 'the absence of quality cinema in the regional languages'.

Benegal: Yes, all that is fine. But has anyone ever wondered what language we are going to do it in?

Kashyap: Of course we can't use English. That kinda defeats the purpose. Hindi is no good either.

Ray, Sen, and Ghatak look up in hopeful anticipation of their mother tongue outnumbering the other languages. Borah and Agarwala seem visibly upset. They are reminded of the decades of Bengali oppression in Assam which removed their language from the diverse map of the country and replaced it with Bengali, and then English. Gopalakrishnan catches the glimmer of hope in the Bengalis' approach and cuts them short.

Gopalakrishnan: Before the Holy triumvirate of Bengali cinema come ahead and explain in great detail that Bengali is the obvious choice for the film, let me suggest that we follow the footsteps of Charles Chaplin and other silent filmmakers.

Ghatak (disgruntled): So the hashtag would be \#ReturnToNature??

Nair: Again with the Romantics? What is this weird obsession? 
Ghatak: Fine! You can have your own hashtag. Why don't you suggest something?

Tension builds up. The directors are apprehensive about the distinctive identities and regional alliances which they have, and they realise it holds in it, potential ground for animosity.

Abraham: Don't you know this is what they tried to do? Just like the British did for two hundred years? They told one of us that the other was making a better film and we went on to do everything in our power to sabotage it. Did we not? Especially the twenty-first-century directors! The government divided you according to languages, states and even what they called "standard" so that one Sanjay Leela Bansali would go up in arms against Anurag Kashyap. Kashyap: You have a point. Let's keep hashtags for later, then. Who has the screenplay? Nair: Screenplay! I didn't even know we had a plot? Where did a screenplay come from?

Ray: I would request everyone to please calm down. We are wasting valuable hours by discussing what to do, and how to do it. I say, carpe diem! We will figure it out as we go along. Something which has been done by greats in fiction writing as well, as I am sure you are aware. I have an idea for the first scene. We will show a bunch of...

[Transition]

The scene fades out into what appears to be the imagination of Ray.

It is a scene within a scene. The directors move like robots to one side of the stage and a cardboard piece is drawn from the wings, which separates the stage into two parts. They stay there unmoved for the entire duration of this metaplay.

A huge camera, placed on a tripod, turns automatically towards the crowd. A loud sigh of regret is heard.

A "CAMERA FOR SALE" board is dropped from the top. The writing is in English.

Someone from the audience shouts out, "Isn't this ironic"

Ray smirks in the other half of the stage and murmurs to himself, "Exactly." That murmur is all but heard by everyone.

The trolleys are full of rust. The mechanical half of the screen now shows a screen. The audience is visibly confused about whether this is a movie or a play.

A few close shots of some of the audience members are shown on that screen. The audience is surprised to see themselves on both sides of the performance. Amitabh Bachchan, Soumitra Chattapadhyay, Rajnikanth are amongst the ones whose faces are shown.

Audience member 1 : What does this mean? Why are we being shown on the screen?

We had nothing to do with it.

Audience member 2: It? What is it? 
All of a sudden, a camera mounts itself on a rusty trolley and slides closer to the front rows. The lens grows big in an attempt to zoom in...

The screen shows a notice which declares

\section{ALL FILMS WRITTEN, PRODUCED OR DIRECTED IN REGIONAL LANGUAGES WILL HENCEFORTH BE NO LONGER AVAILABLE FOR PUBLIC CONSUMPTION IN ANY AND ALL STREAMING SERVICES}

Audience member 3: Are you implying that we are responsible for this? That we did not appreciate films made in regional languages enough for the Capitalist giants to be interested in them?

Audience member 2: No they can't be implying that! We are the next generation.

Our great grandparents were no better! There was not a single streaming service, even a hundred years ago in 2021, where one could watch all the movies of Mrinal Sen, Mani Ratnam or Adoor Gopalakrishnan. What is the point of blaming this on us, when our ancestors did most of the damage? Audience member 4: So what? We could have done everything in our power to bring some change, could we have not? We managed to get Disney to produce 17 Star Wars films. We could have surely gotten them to have at least SOME regional language films.

The directors, standing perfectly still, straighten their spine a little. The beam of pride is reverberating across the stage. Ray smiles the widest because he knows the age-old trick, from the times of Shakespeare, has worked again!

The camera turns towards the audience, clicks, and its shutter closes. The photo it clicks is that of the audience members, their heads down in shame.

The photo comes up on the screen presently, and slowly loses all its colour. The word "symbolic" is heard from the crowd.

Audience member 1: Is there absolutely nothing we can do?

Audience member 2: Oh please! When have we ever managed to change the decision of this government?

Audience member 3: We can still try. Let's take it up to them and attempt a mass unsubscription?

The camera, which had rolled itself towards the audience in unprecedented belligerence, rolls back to its position. The audience takes it as a positive hint. The screen starts showing snippets of colour here and there, much like the last few minutes of Goopey Gayne Bagha Bayne. 
Cumballa Hill, Mumbai, Maharashtra. The Censor Board's former office. Now, a heritage site with a handing image of Pehlaj Nihalani, who is now considered to be the greatest Chairman of the Board's history. The CEOs of Netflix, Amazon and Disney, Baldwin Matthews, Timothy Bezos and Samantha Clarke respectively, have decided to meet in this rather odd location, just to get a hint of the situation at hand.

Clarke: Why has the subscription rate gone down so rapidly over the past few weeks?

Can anyone tell me if its just Disney or all of us?

Bezos: Amazon Prime has had many people discontinue their subscription as well.

The signature Netflix theme plays in the background with the word "Shame" falling down on the stage on a banner.

Bezos: Yea, they have some sort of rebel movement going on. I did get a tweet along with the hashtag \#BringBackRegionalFilms.

\section{ACt i SCEne III}

The stage is divided into two parts. On the left hand, all the directors are holding up placards that have "Bring Back Regional Films" written in their mother tongues. The right side of the stage has a screen that shows a zoomed-in shot of the directors' faces. The audience members who speak Bengali are reminded of a rather popular song created in 2021 by the resistors against fascism called "Nijeder Mawte Nijeder Gaan" [Our song and our opinion]. The stoic solemnity in their faces arouses hopes in the hearts of the film enthusiasts. All the placards have a border made of ancient film reels.

The words "apt usage of available material" is heard from the crowd.

The lights on the stage are dimmed out. It slowly becomes dark. After a pause of a few seconds, the lights are back on. A different set-up is visible.

The confederation of CEOs has decided to fly to Kolkata to have an interdimensional talk with the directors who have caused this uprising of the masses. The time is that of sunset. They have decided to meet at Princepghat, right next to where Fort Williams once stood.

Matthews: Where are they? They are not supposed to be late.

The other two look at the sun and then breathe a sigh of regret. They wonder when will Matthews understand. One of them is dangerously close to a facepalm.

They wander around. A seller of fast food identifies them as foreigners and sells them things at 10 times the original price. The city smiles wryly. 
As the darkness descends upon the scene, some whispers of the heart are heard. The people around the area fade into darkness. The three billboards outside Fort Williams, Princepghat display the heinous slogans

\section{DOWN WITH THE LANGUAGE IMPOSITIONS BRING BACK REGIONAL FILMS STREAMING GIANTS, ARE YOU STILL WATCHING?}

The band of directors step in. It is noted that only Ray, Gopalakrishnan, Agarwala and Abraham have come.

Bezos: This is ridiculous. Why have only the four of you come?

Ray: Why the streaming giants can send their representatives, and we can't? We still live in a democracy, though we know that you don't.

Clarke: Let's not get carried away. Tell us what you want.

Gopalakrishnan: Nothing.

Matthews: What do you mean? We are ready to talk about the terms and conditions of bringing back a lot of regional films to our streaming services! We have talked it over amongst ourselves!

Agarwala: We don't need your sympathy.

Bezos: Then what will happen to the films? They will get lost and people will eventually forget that these films existed. Why don't you take our generous offer?

Ray: Let me quote myself and say, "I don't take money for work that I have not done." In this case, we know you are trying to set us up for a betrayal in the future so that no one can bring up an issue like this again.

Abraham: Yeah exactly. Don't you think we already know by now that all you'll do is buy the streaming rights for some of these movies and dump them in one corner of your websites, make them unavailable for most of the countries, and not give them subtitles? The list goes on. You might even use Search Engine Optimisation to make sure no one ever finds these movies, as well.

There is visible panic on the faces of the three foreigners. Suddenly, the stage turns 180 degrees and the backstage comes to the forefront. A huge bundle of papers, held together by paperweights. It is not clear what the paperweights are. The three walls are lined up with posters from innumerable regional films. Some of them are torn apart, some are old and indistinguishable. A zoom-in to the paperweights reveals them to be stacks of CDs and DVDs which were declared obsolete more than a century ago.

The stage shakes up a bit, resembling something of an earthquake. The paperweights fall off onto the side of the audience. Surprisingly, the audience members (some of whom are recognised from a previous scene) are carrying jute bags and DVD holders. 
The CDs and DVDs fall on the floor of the hall. The audience members make a line, pick up the ones they want to, and go back to their seats. Without any paperweights, the huge bundle of papers fly up and about in the air. People realise that the papers contain the scripts for some stellar regional films. They are flying in the air when the stage takes another 180-degree turn, revealing the sweating faces of the three CEOs and the contented faces of the directors.

Audience member 1: But. I have so many questions

Audience member 2: Like what? They don't have time to answer all of your questions.

Ask the most pertinent one.

Audience member 1: How did a bunch of dead directors manage to communicate to the ones who live and breathe?

Audience member 2 smiles. Their eyes glow in the happiness which they feel.

They point towards the stage. A huge placard is being rolled down on the stage. It slowly unfurls itself, clearing most of the doubts of the people about the discrepancies in this play.

The placard reads,

\section{WILLING SUSPENSION OF DISBELIEF}

\section{Curtain Call.}


